\title{
1. Charting the evolving landscape of services trade policies: Recent patterns of protection and liberalization Martin Roy ${ }^{1}$
}

\section{INTRODUCTION}

The widely shared objective of resisting protectionism in the context of the economic crisis has led to a greater monitoring of changes in trade policies. Increased transparency in the adoption of new trade-facilitating and trade-restrictive policies has been spurred by the G-20 Leaders' Declaration of 2008, which instructed the WTO, together with the OECD and UNCTAD, to monitor and publicly report changes in trade policies.

This greater attention to trade-facilitating or restricting policies has mostly focused on goods trade, and only limited attention has been cast on new measures affecting services and on their specificities. ${ }^{2}$ However, greater attention and transparency regarding policies affecting trade in services is greatly needed. For one, information on measures applied in services has historically been scant, which has made analysis of the impact of reforms and protection more difficult. It has also made negotiations more arduous, as multilateral negotiations in particular have not managed to bind existing levels of access. Second, given the weight of the services sector in domestic economies and inter-linkages with other sectors, the positive or negative effect of trade-facilitating/restrictive measures can be much

1 The opinions expressed in this chapter should be attributed to its author. They are not intended to represent the positions or opinions of the WTO or its Members and are without prejudice to Members' rights and obligations under the WTO. Any errors are attributable to the author.

The author would like to thank Yaxuan Chen, Stefan Froschl, Laura Gomez Bustos, Khadiga Hafez, Joscelyn Magdeleine, Habone Osman Moussa, Kätlin Pertel, Ester Rubio, David Smart, Ngan Vu, and Evgeniia Zhuravleva.

2 See for example: European Commission, 'Tenth Report on Potentially Trade-Restrictive Measures Identified in the Context of the Financial and Economic Crisis', 1 May 2012-31 May 2013', Brussels, http://trade.ec.europa. eu/doclib/docs/2013/september/tradoc_151703.pdf; Simon Evenett, 'The Global Trade Disorder; the 16th GTA Report', CEPR, GTA, 2014 http://www.globaltradealert.org/sites/default/files/GTA16.pdf. 


\section{Research handbook on trade in services}

more extensive. For example, a hypothetical rise in protectionist measures affecting services in the wake of the economic crisis would have had a large impact on the world economy, as well as on world trade: even if services trade represents a small share of world trade (slightly above 20 per cent), when considering services inputs in the production of goods traded, services represent 45 per cent of the value added in trade values. In addition, the value of services trade does not take into account the principal way of supplying services internationally, namely through a commercial presence abroad (mode 3); given that most of world foreign direct investment (FDI) now takes place in services sectors, increased protectionism would have far reaching effects.

Finally, the direction and characteristics of recent policy changes should be informative of the opportunities or constraints for ongoing services negotiations, either multilateral or preferential. While an increase in tradeliberalizing reforms should provide an environment conducive to the undertaking of greater market access bindings, a burst of trade-restrictive measures would likely not provide a setting leading to more commitments. Similarly, ascertaining which countries, sectors, and modes are associated with trade-restrictive/facilitating measures carries useful insights for negotiations.

On the basis of information contained in the I-TIP Services database, ${ }^{3}$ this chapter provides an overview of policy changes taking place in relation to services trade since 2000. It highlights relevant trends in trade restrictiveness and openness over time and examines the characteristics of countries, sectors, and modes of supply where most trade-facilitating/ restrictive measures have been undertaken.

The following section describes the data used for the analysis and briefly discusses what common political economy perspectives would lead us to expect as regards the direction and characteristics of policy changes in services. The third section presents the results of the analysis of policy changes, and the last section concludes.

\section{INFORMATION ON THE DATA USED AND EXPECTED FINDINGS}

Work by the World Bank and the OECD has permitted painting a picture of existing restrictions to services trade. From such a picture, we know, among other things, that the level of restrictions to services trade is still

\footnotetext{
3 https://i-tip.wto.org/services/.
} 
high; that levels of protection are lower in OECD countries; that developing countries in Asia tend to be more restrictive than in Latin America or Africa; and that such sectors as transport and professional services are overall more protected than financial, telecommunication, or retailing services. ${ }^{4}$

The picture of existing restrictions does not necessarily tell us a lot about recent policy trends though. From the literature, we know that undertaking policy reforms in services is usually more complex than doing so in relation to goods trade. Indeed, measures affecting trade in services are embedded in domestic regulatory regimes. Reforms need to factor in a diversity of regulatory objectives, and tend to be implemented incrementally. Accordingly, we can safely expect the existing pattern of applied measures to largely reflect policies that have been in place for a long time; such current pattern may not be most instructive about recent directions of services trade policy-making.

Information on policy trends in services is not as readily available as for trade in goods. While the continuation of recent data collection efforts by the World Bank and OECD would, in the future, permit a more systematic tracking of trends over time, these datasets currently provide a static picture. Furthermore, unlike for agreements on trade in goods, notification obligations under the GATS do not constitute a significant source of information on the evolution of applied policies.

Indeed, notification obligations under the GATS mandate Members to notify only a small subset of their policies. The notification obligation of Article III:3 of the GATS has three important limitations. First, it only provides for notification of new measures or changes in existing measures. Accordingly, there is no obligation to more generally notify measures currently being applied. Second, and more importantly for our purposes, the notification obligation is only relevant for sectors where Members have undertaken sector-specific commitments. Since the majority of WTO Members do not have commitments in the majority of sectors, this is an important limitation. Third, the notification obligation is limited to those measures that 'significantly affect trade in services'. While the scope of the agreement relates to measures 'affecting trade in services', the somewhat imprecise meaning of 'significantly' affecting services trade may have contributed to another limitation of sorts. Finally, Members are unlikely to

4 Ingo Borchert and Aaditya Mattoo (2009), 'The Crisis Resilience of Services Trade', World Bank Policy Research Working Paper (WPS4917), Washington DC. See also the OECD STRI at: http://www.oecd.org/tad/services-trade/services-tr ade-restrictiveness-index.htm. 
take active steps to notify new restrictive policies, especially if these may be in violation of their existing GATS obligations.

While such factors do not justify non-observance of GATS Article III:3, the reality is one of low compliance by Members. As reported by the Secretariat to the Council for Trade in Services in May 2014, 514 notifications had been received from the entry into force of the GATS in 1995 up to 2013, an average of about 27 per year. ${ }^{5}$ More strikingly, a total of 73 Members (counting EU Member States individually) had made one or more notifications over the same period. In other words, the majority of Members had made no notifications at all, and most had only made a handful. Indeed, three Members (Albania, China, and Switzerland) accounted for almost half of the 514 notifications made.

In view of the above-mentioned limitations, we rely here on the information found in the I-TIP Services database (https://i-tip.wto.org/services/). I-TIP Services is a unique source of information on services policies that, among other things, provides easy access to information on applied services policies from a variety of public sources (World Bank, APEC, UPU, WTO), including by permitting searches by sector and Member. ${ }^{6}$ For our purposes, it allows us to isolate those instances where changes were made to applied policies, whether towards greater liberalization or trade restrictiveness.

Within I-TIP, the information that most often proves relevant in terms of highlighting policy changes comes from WTO sources, notably information from the Trade Policy Review (TPR) process, the Director General's Trade Monitoring Reports, and notifications under Article III:3 of the GATS. Obviously, such information cannot be said to be exhaustive. TPRs are conducted every few years, the DG Monitoring report is a relatively recent exercise, and GATS notifications have limitations, as noted above. But the diversity, quantity and quality of sources used suggest that it is the most complete currently existing. Measures mentioned in such other sources as Global Trade Policy Alert or different national monitoring efforts (e.g., the European Union's Market Access database or US Trade Representative's annual National Estimate of Foreign Trade Policy Barriers) have been picked up by other sources of information compiled in the I-TIP Services database.

The dataset used here covers policy changes in applied services regimes that occurred from 2000 onward, and covers all WTO Members. So as to

\footnotetext{
5 WTO, 'Council for Trade in Services - Report of the Meeting Held on 8 May 2014', Note from the Secretariat, 27 May 2014, Geneva, S/C/M/117.

6 I-TIP Services is an integrated database that provides access to information not only on applied regimes, but also on GATS commitments and MFN exemptions, services commitments in RTAs, and services statistics.
} 
avoid capturing a wide range of measures that carry only minor consequences for foreign service suppliers and have limited impact on services trade, policy changes are here defined to cover measures that affect access to markets and conditions of operation by foreign service suppliers. Such measures typically fall within the scope of market access or national treatment, as defined in Articles XVI and XVII of the GATS. ${ }^{7}$

From our current knowledge of services trade policies, what policy trends would we expect to find? On the one hand, the fact that barriers are overall higher for services than for goods, as well as the more limited international bindings than for goods, may lead us to expect that recent years have seen new trade-restrictive measures outweigh trade opening initiatives. ${ }^{8}$ On the other hand, the special nature of services as infrastructure sectors that drive economies' competitiveness and on which all other local industries rely (including for exports) may have reduced or offset demands for protection. The demand for cheap inputs by downward users, as well as increasing reliance on vertical integration and international supply chains may drive unilateral liberalization and help keep protectionism in check. ${ }^{9}$ Since various services sectors are key to cross-border supply chains and key inputs to other sectors (e.g., finance, telecommunications, transport, distribution services), we may expect that this factor would exert considerable influence.

Moreover, the fact that services trade covers investment may also limit the introduction of restrictive measures. Indeed, the introduction of measures to restrict foreign supply under mode 3 would likely be less common

7 A few other measures deemed to facilitate trade or afford protection are also covered, as it seemed preferable not to be overly legalistic and try to draw subtle distinctions between what was covered by national treatment/market access and what was not. A number of policy changes that have been notified under GATS Article III:3 are not covered in the dataset because they cannot be said to be measures falling under market access/national treatment, nor do they appear, from the description provided in the notification, to have a significant effect on foreign suppliers' conditions of access and operation. Further, the dataset does not contain information on government procurement policies, which are largely excluded from GATS coverage.

8 Looking at policy responses to the financial crisis, Gawande, Hoekman and Cui find that WTO bindings exerted a limiting influence on countries' trade policies as regards trade in goods: Kishore Gawande, Bernard Hoekman, and Yue Cui (2014), 'Global Supply Chains and Trade Policy Responses to the 2008 Crisis', The World Bank Economic Review.

9 Kawande, Hoekman and Ciu (2014), above n 8; Richard Baldwin (2010), 'Unilateral Tariff Liberalization', The International Economy 14: 10-43. 
because they would negatively impact companies operating within the national economy and their employees. ${ }^{10}$

In terms of modes of supply, one may consequently hypothesize that mode 3 would attract a greater proportion of trade opening measures than, for example, mode 4, which involves the temporary movement of foreign natural persons, and which has proved more politically sensitive in the past, as reflected by limited multilateral commitments in this area. Since it is akin to goods trade, mode 1 (cross-border supply) may be expected to attract more restrictions than mode 3 , although, at the same time, the increased digitization of services trade would seem to make it difficult for governments actually to impose barriers to the cross-border flow of services. ${ }^{11}$

For a combination of reasons, we may also expect developing countries to have been less trade liberalizing than developed economies: their current restrictions are higher, they have fewer commitments (either at the WTO or in preferential trade agreements (PTAs)) that would constrain their ability to raise barriers, and their services exporters, which would resist the introduction of restrictive measures by fear of being reciprocated against in foreign markets, do not have the same political weight as they have in developed economies.

In terms of sectors, the economic crisis - as well as the drop in trade flows in its aftermath - may lead us to assume that the financial services sector has attracted a high share of new restrictive measures. We may also suppose that sectors that are currently relatively more restricted would attract more new restrictive measures (and less liberalizing initiatives), i.e., transport and professional services vs. telecommunication or retailing services.

10 See, for example: Rudolf Adlung and Martin Roy (2005), 'Turning Hills into Mountains? Current Commitments under the General Agreement on Trade in Services and Prospects for Change', Journal of World Trade 36(6): 1161-94.

11 Adlung and Roy (2005), ibid.; Bernard Hoekman, Aaditya Mattoo and André Sapir (2007), 'The Political Economy of Services Trade Liberalization: A Case for International Regulatory Cooperation?', Oxford Review of Economic Policy 23(3): 367-91; Aaditya Mattoo and Sacha Wunsch-Vincent (2004), 'Pre-Empting Protectionism in Services: The GATS and Outsourcing', Journal of International Economic Law 7(4): 765-800. 


\section{PATTERNS OF NEW LIBERALIZING AND TRADE-RESTRICTIVE POLICIES IN SERVICES}

As of the end 2014, the I-TIP Services database contained 360 records of policy changes since $2000 .{ }^{12}$ Figure 1.1 shows the number of policy changes per year from 2000 to 2014 , distinguishing between liberalizing and trade-restrictive policies. It highlights that, overall, trade opening initiatives have clearly outweighed trade-restrictive ones. Indeed, of the 360 policy changes recorded in the period under review, 77 per cent are liberalizing and 23 per cent are towards more trade restrictiveness. This contrasts with the gloomier picture on goods, and contradicts what may have been expected on the basis of existing levels of protection (high) and commitments (low).

Trade-facilitating reforms have occurred throughout the decade, and

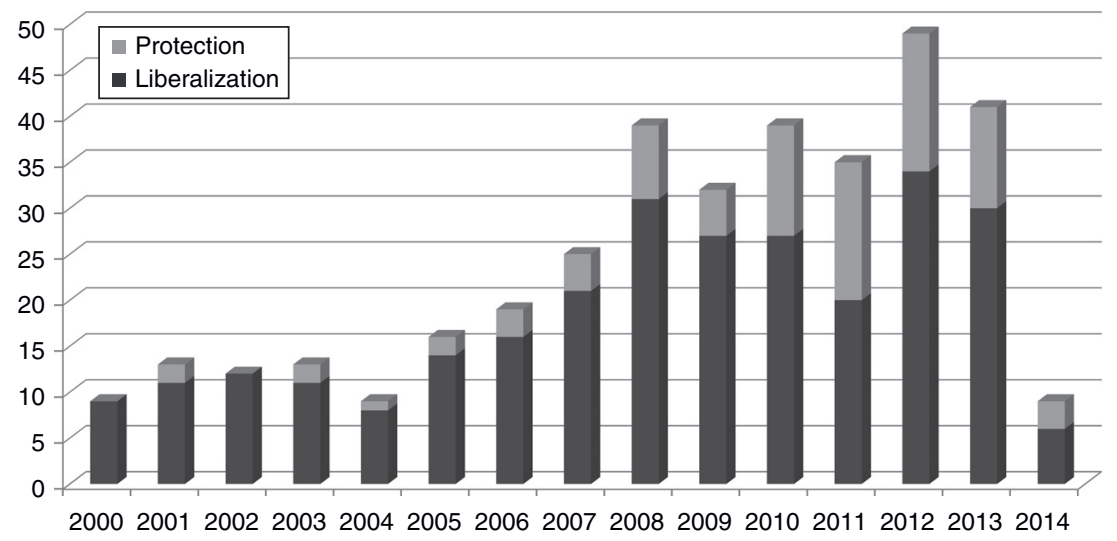

\section{Figure 1.1 Policy changes over time}

12 For ease of reference, we use interchangeably the terms policy changes and measures. However, in a strict sense, the number of records of policy changes is not necessarily the same as the number of measures. Indeed, a given policy change may involve a set of different measures, e.g., various modifications to the foreign ownership ceilings in different sectors in combination with modifications of nationality requirements for boards of directors, or the concurrent relaxation of the duration of stay for, say, intra-corporate transferees and independent professionals (mode 4). The total numbers of policy changes in this chapter therefore capture the policy change implemented at a given point in time, and not the total number of types of measures that may have been affected. Indeed, counting policy changes in services is not as straightforward as counting the number of anti-dumping investigations, for example. That said, later on, we analyse policy changes on the basis of a classification by type of barrier. 


\section{2}

Research handbook on trade in services

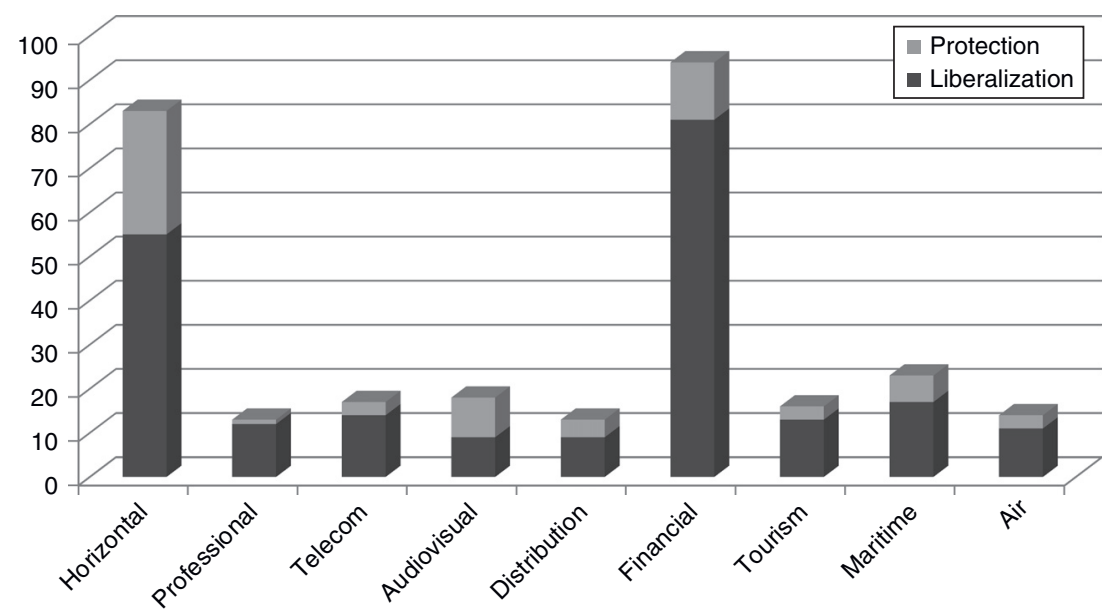

Figure 1.2 Policy changes by sector

have continued despite the financial crisis. Lower numbers of policy changes for 2014 simply reflect the lag between the time the reforms occur and the time they are reported. The total number of policy changes also speaks to the dynamism of services trade, attesting to governments' attempts to react to the changing economic realities, even if services reforms are often more complex to put in place.

That said, the number of restrictive measures, as well as their share of total policy changes, has increased after the crisis, suggesting that moves towards protection may have outweighed liberalization efforts for certain countries, sectors or modes of supply. Moves toward protection serve to show the value of market access bindings in trade agreements: international commitments carry value not only in the rare situations where they may, by themselves, induce new liberalization, but also when they bind existing access and therefore serve to prevent rollbacks. Obviously, the introduction of these new trade-restrictive measures has been made possible because of the gap between applied and bound regimes.

Figure 1.2 shows how trade-facilitating and restrictive policy changes are distributed across services sectors. Most policy changes relate either to financial services or are cross-sectoral in nature. Surprisingly, the new measures introduced in the financial sector have overwhelmingly been towards greater openness ( 86 per cent), despite the financial crisis and the troubles experienced by a number of institutions.

The high proportion of 'horizontal' trade-restrictive measures (34 per cent of policy changes, compared with 23 per cent for all sectors) is 


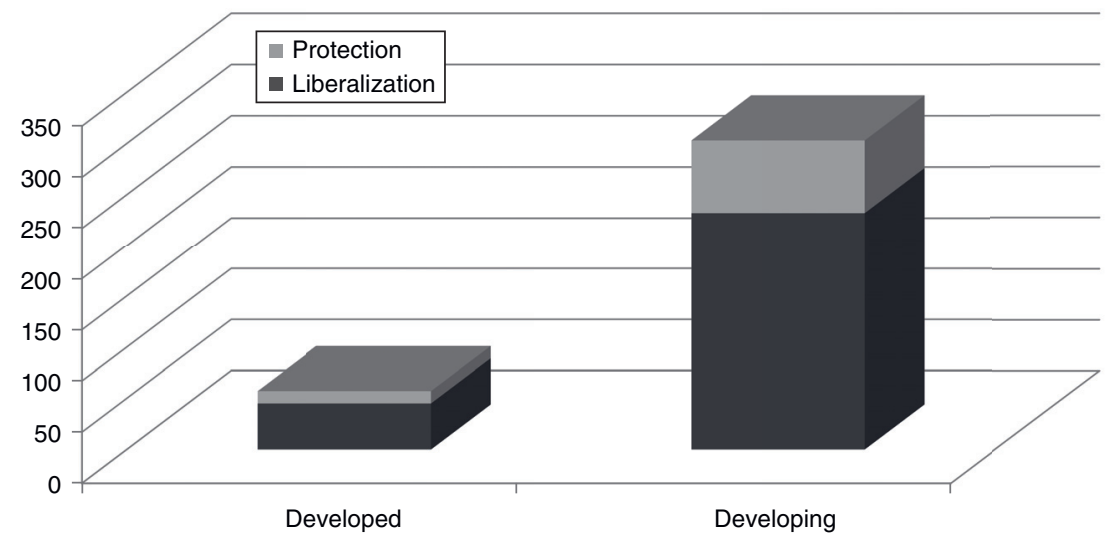

Figure 1.3 Policy changes by Members' level of development

also unexpected. Indeed, the political economy literature suggests that well-organized and concentrated domestic industries are more effective in obtaining protection, which would suggest more limited cross-sectoral demands for (and offer of) protection.

Audiovisual services is the only sector where the number of new restrictions is higher than that of new trade opening reforms. This is a sector where few Members have multilateral commitments. And most of those Members that have introduced new trade-restrictive policies in the sector had no multilateral commitments in the sector.

The sectoral pattern of policy changes also seems to differ from that of existing restrictions. Indeed, the proportion of policy changes that are trade restrictive is higher than the overall average for the sectors of distribution, maritime transport, and audiovisual services, while it is lower than average for telecommunication, financial, tourism, and professional services. This contrasts with the existing pattern of protection, where, according to the World Bank, professional services are relatively more restricted, and distribution services less so.

Figure 1.3 shows that the proportion of trade-restrictive measures is similar for developing and developed economies: 23 per cent of policy changes in developing economies were trade restrictive, while that proportion was of 21 per cent in developed economies. Accordingly, even though developing economies account for a much bigger share of all policy changes ( 84 per cent of all measures) and therefore have more traderestrictive measures in absolute terms, both groups account for a similar mix of liberalizing and trade-restrictive policy changes. The expectation that developing countries, because they have fewer commitments, limited 


\section{Research handbook on trade in services}

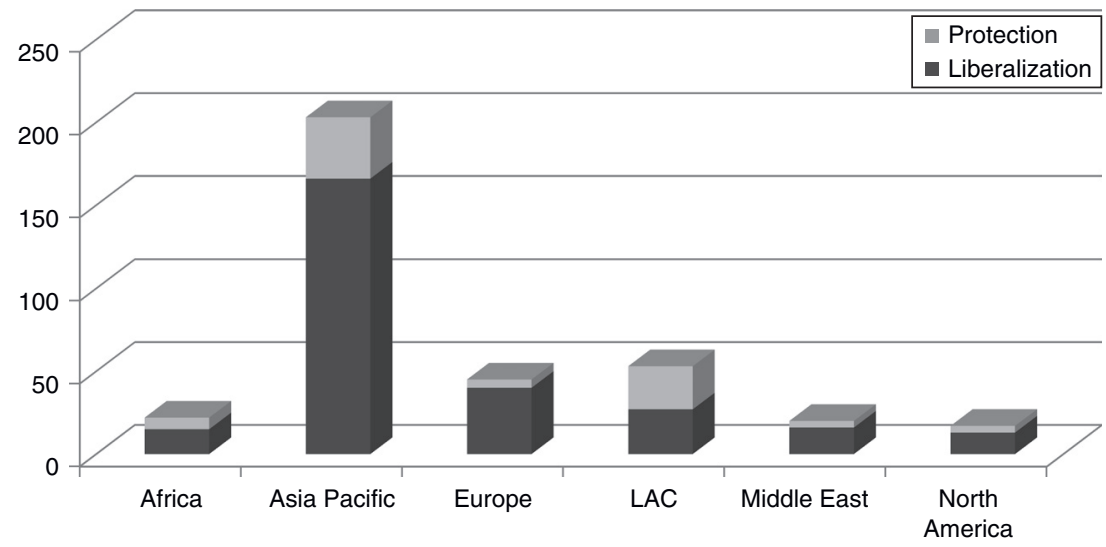

Figure 1.4 Policy changes by region

export interests in services, and more restrictive services regimes, would be significantly less liberal than developed economies is not borne out by available information.

China is, by far, the country with the highest number of policy changes in the dataset. This naturally reflects the evolving national policy landscape since WTO accession. The relatively higher number of policy changes for China is also partly due, however, to the greater amount of information available, including from WTO sources, where China, in addition to TPRs, has also been subject to a specific Transitional Review Mechanism pursuant to its Protocol of Accession. Out of the 51 policy changes that concern China in the dataset, the overwhelming majority are trade facilitating (47). Such liberalization is almost solely focused on mode 3 , with all but one of the liberalizing policy changes relating to commercial presence. A good number of these measures are cross-sectoral, while others result from the gradual implementation of WTO commitments (e.g., in telecommunications, distribution services), and the recent establishment of the Shanghai Free Trade Pilot Zone, which relaxes measures affecting foreign suppliers in such sectors as engineering, construction, education, medical, tourism, transport or financial services. ${ }^{13}$

Looking at policy changes by region provides certain interesting insights (Figure 1.4). Asia-Pacific is most dynamic not only in terms of growth

13 WTO, 'Report to the TPRB from the Director-General on the Financial and Economic Crisis and Trade-Related Developments (1 March-19 June 2009)', 15 July 2009, p. 23, para. 65 and p.60, Annex 4. 


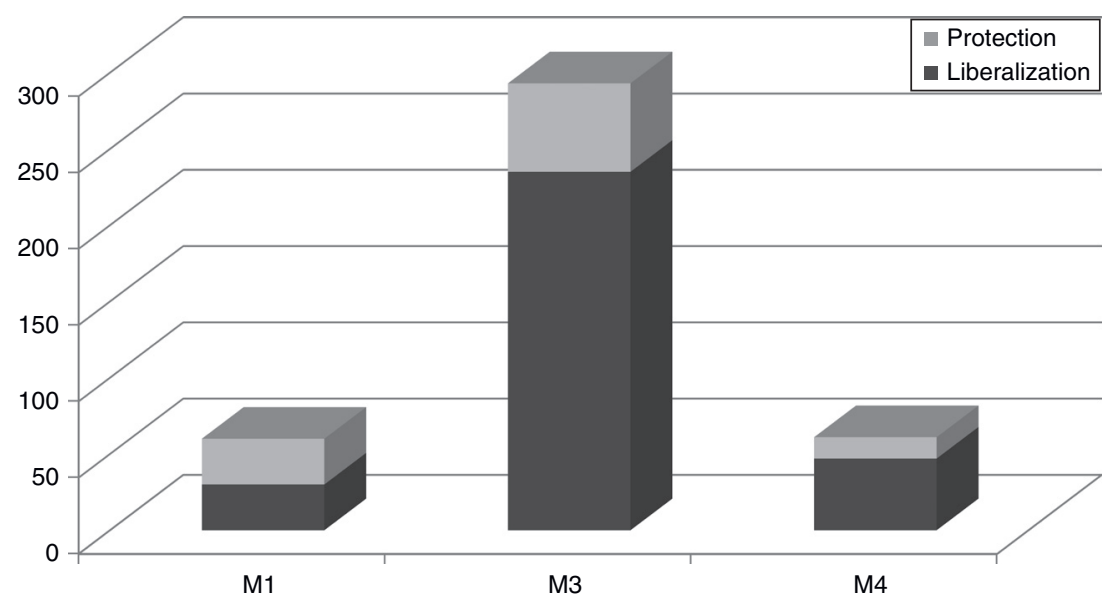

Figure 1.5 Policy changes by mode of supply

in trade flows and involvement in trade negotiations, but also in terms of trade policy developments. It is the region with most recorded policy changes, both trade restrictive and trade facilitating, although the latter are predominant. Trade-opening reforms clearly dominate in other regions, except in Latin America, which is the only region where the number of trade-restrictive policy changes outnumbers trade-facilitating ones. This is not to say that all Latin American countries have been more restrictive over the last 15 years. Clearly divergent paths appear to have been followed by different countries in the region: most trade-restrictive policy changes in the region have been attributable to a handful of countries, while trade liberalizing reforms have predominated in others.

The picture in terms of modes of supply also brings some surprises (Figure 1.5). Matching expectations, mode 3 is where most liberalizing measures have been undertaken. However, it is also the mode where, in absolute terms, the greater number of trade-restrictive policy changes have been implemented. Cross-border supply is the mode with the highest proportion of trade-restrictive measures. That is consistent with what the political economy of trade suggests, although it also shows that despite technological advances governments are able to find ways to impose restrictions under this mode of supply. Examples include commercial presence requirements, limits on credit card purchases, and prohibitions on certain cross-border insurance and reinsurance operations. Among other things, this suggests that there is value in binding existing openness under that mode so as to prevent future introduction of restrictive measures.

More surprisingly, mode 4 is associated with the lowest proportion of 

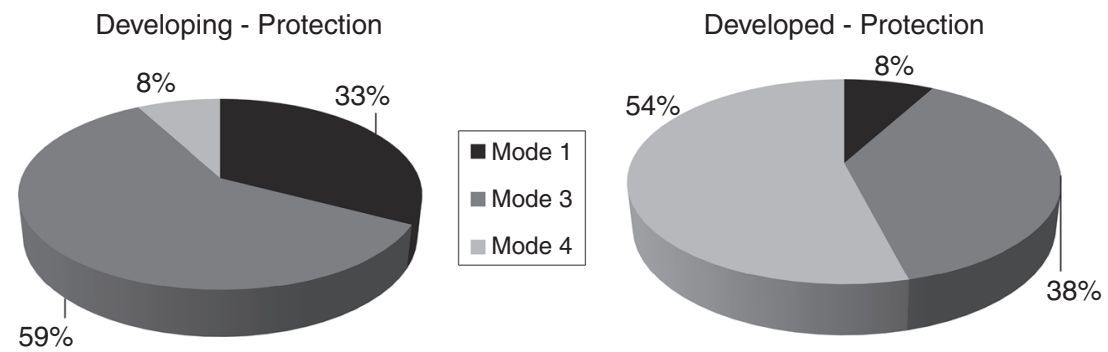

Figure 1.6 Distribution of trade-facilitating measures by mode of supply for developed and developing countries

trade-restrictive measures. It is also the mode of supply with the lowest number of trade-restrictive measures adopted. But it is not only a mode that has resisted pressures for protection: it is also one where governments have enacted a good number of liberalizing measures over the last years, despite reluctance to undertake binding commitments in international agreements and the expected sensitivity of this form of services trade. Trade-facilitation measures in this area have taken the form of expanded categories of natural persons eligible for temporary stay, extended periods of stay, and the relaxation of various procedures and requirements in connection with the entry of foreign natural persons.

Another way to look at the modal picture is to see how liberalizing measures (or trade-restrictive ones) are distributed by mode of supply according to the implementing countries' level of development. Figure 1.6 shows that for all Members, the bulk of trade-facilitating measures has occurred in relation to mode 3, although much more so for developing countries. For developed countries, a much greater share of trade-facilitating policy changes - a third of all such measures - relate to mode 4 .

Figure 1.7 illustrates that the pattern of trade-restrictive policy changes is quite different for developing and developed countries. For the latter, most restrictive measures relate to mode 3 , and a high proportion (33 per cent) to cross-border supply. In contrast, the majority of trade-restrictive measures of developed countries affect mode 4 , though it should be kept in mind that the absolute number of restrictive measures of developed countries is low and that developed countries have adopted many more trade-facilitating measures in relation to that mode of supply. A number of restrictive measures relating to mode 4 concern labour market tests.

The dataset also contains information on the type of trade barriers put in place. In relation to mode 3, most of these have taken the form 
Developing - Liberalization

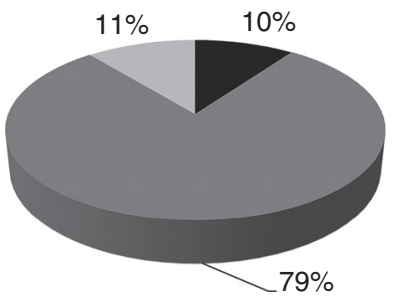

Developed - Liberalization

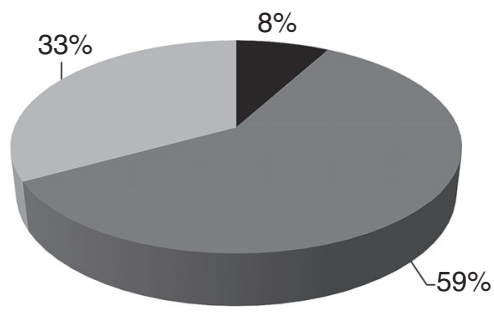

Figure 1.7 Distribution of trade-restrictive measures by mode of supply for developed and developing countries

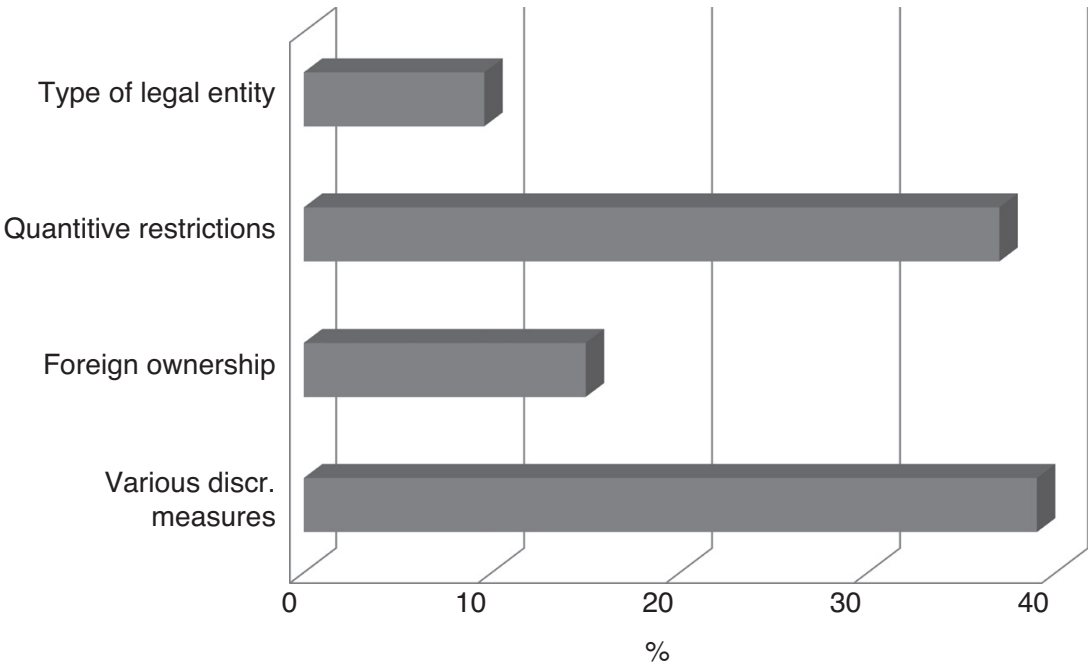

Figure 1.8 Trade-restrictive policy changes affecting mode 3, by type of measure

of limitations to market access, as defined in Article XVI of the GATS. Quantitative restrictions - on either the number of suppliers, transactions, or operations, whether discriminatory or not - have been more common than limits on foreign ownership, a more traditional tool, or restrictions on the type of legal entity. Still, almost 40 per cent of these policy changes concerned discriminatory measures other than those falling under Article XVI of the GATS (Figure 1.8). They took the form, for example, of fees, qualifications, authorizations, licensing procedures or requirements that discriminate between foreign and domestic suppliers/services. 


\section{Research handbook on trade in services}

\section{CONCLUSION}

Examination of policy changes in services since 2000 reveals a significant push towards greater liberalization, which has continued despite the economic crisis. While PTAs sometimes do lead to new liberalization, ${ }^{14}$ the preponderant share of such reforms likely occurs autonomously. This liberalization trend suggests that governments have come to value the economic benefits of relaxing barriers to services trade for their consumers, for attracting FDI, and for increasing the competitiveness of their own companies that rely on services inputs, including firms exporting goods. This was not a foregone conclusion given protectionist pressures and the already high level of trade restrictiveness in a number of sectors, modes, and countries. Concurrently, this trend may also be due, at least in part, to demands from downward users for cheaper and better quality services as inputs. The greater role of global supply chains, and the essential role of various services in their proper functioning, may have induced a different political economy dynamic than what had traditionally prevailed for trade in goods. Further research to formally test these hypotheses would be valuable.

Developing countries have adopted a much greater number of policy changes - restrictive as well as facilitating ones - than developed countries. But unlike what may have been reasonably expected, developing countries have not, as a group, introduced proportionally more trade-restrictive measures than developed countries; trade-restrictive measures have accounted for a similar share of total policy changes in the two groups. Analysis of policy changes by mode of supply also went against expectations, principally because mode 4 is associated with a high proportion of liberalizing policy changes, mode 1 with a high proportion of restrictive ones, and mode 3 with a high absolute number of trade-restrictive policy changes.

Even though liberalization initiatives have consistently outweighed trade-restrictive ones, a non-negligible number of new restrictive measures have been put in place in recent years, and these are often significant in their impact, including because they affect economically important sectors and modes of supply, typically mode 3 . This further underscores the need to pursue the monitoring of policy changes, including at the WTO, therefore bringing more transparency to this process and facilitating discussion of the impacts and costs of such actions. These new restrictive policies also

14 Martin Roy, Juan Marchetti, and Hoe Lim (2007), 'Services Liberalization in the New Generation of Preferential Trade Agreements: How Much Further than the GATS?', World Trade Review 6(2): 155-92. 
serve to highlight the value of trade commitments, including those that are sometimes belittled as 'merely' binding the status quo.

The importance of autonomous liberalization also underscores that negotiations in services trade should not be dominated by mercantilist considerations, whereby commitments are made if reciprocated by other countries. Indeed, liberalization largely occurs independently of negotiations, out of self-interest.

Overall, this evolution of applied regimes bodes well for trade negotiations. The push towards autonomous liberalization provides a positive environment for the undertaking of commitments: agreeing to bind a certain level of access should be politically easier in a context where governments are taking the bolder steps of undertaking reforms to modify existing practices. Autonomous liberalization also increases the potential for further commitments in trade agreements, as governments and domestic actors see value in giving credibility and certainty to the reforms undertaken by binding them through international agreements. Further, the fact that a number of new restrictive policies keep springing up argues in favour of improving WTO Members' levels of commitments on trade in services. Currently, many services sectors are uncommitted; and many sectors are committed at a level that is more restrictive than the applied regime. Obviously, reaching levels of commitments that match the applied practice would prevent new trade-restrictive measures, or at least provide recourse in the event these are put in place in violation of international commitments.

But, in view of trends in policy changes, in what forum should such international commitments be undertaken? While services PTAs have proliferated in recent years, available information suggests that a good number of the countries that have undertaken reforms are either not part of this evolving web of preferential agreements or, if they are, they have not been involved in PTAs yielding ambitious commitments. This suggests, for one, that there is a potential for further commitments in WTO negotiations on services, and that the GATS holds most promise in terms of consolidating the autonomous liberalization taking place around the world and yielding commitments that would best prevent future eruptions of protectionism. PTAs, by the very nature of their limited country coverage, would only permit meeting these objectives in a limited way. One can take the example of TiSA, the largest and most important preferential negotiation on services currently taking place, to illustrate. ${ }^{15}$

15 The negotiation of the Trade in Services Agreement (TiSA) involves 24 countries (as of 1 May 2015): Australia; Canada; Chile; Colombia; Costa Rica; the 


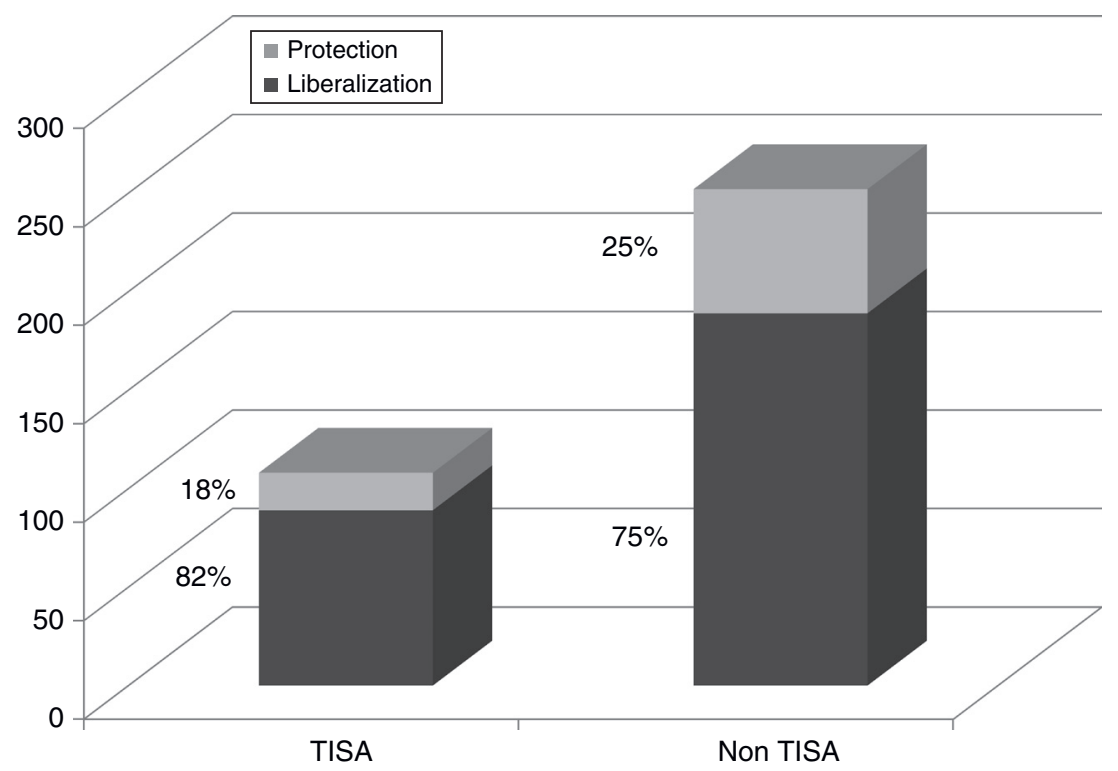

Figure 1.9 Policy changes for TiSA participants and non-participants

Even though participants to the negotiation of the TiSA account for over two-thirds of world exports of trade in services, Figure 1.9 shows that non-TiSA participants (e.g., India, Brazil, South Africa, ASEAN countries, China) have accounted for a much greater number of policy changes since 2000, both trade-restrictive and trade-facilitating ones. While, as expected, the policy changes put in place by TiSA participants have been trade facilitating in a greater proportion than those of nonTiSA participants, the difference is not great, as in both cases liberalizing policy changes have outweighed trade-restrictive ones. What Figure 1.9 highlights is that most of the policy activity, especially steps towards greater liberalization, is occurring outside TiSA. This highlights that services PTAs can only reach their - arguably - most important objectives (consolidating liberalization and preventing future protection) in a partial way. TiSA, given its country coverage, would not bind a great number of recent liberalizing reforms that have taken place worldwide, and would

European Union; Hong Kong China; Iceland; Israel; Japan; Korea; Liechtenstein; Mexico; New Zealand; Norway; Pakistan; Panama; Paraguay; Peru; Switzerland; Chinese Taipei; Turkey; the United States; and Uruguay. Although negotiated in Geneva, the TiSA is not a WTO negotiation. 
not prevent a potentially significant number of future trade-restrictive measures to be introduced.

Maybe more importantly, the momentum towards liberalization and the associated pre-disposition toward greater commitments would not be fully utilised if only preferential avenues were followed. This might be a lost opportunity. That being said, it also rests with those that are not participating in TiSA or otherwise not involved in various ambitious preferential negotiations to ensure that their trade negotiators have, in the WTO, the authority to adopt a negotiating stance that matches that of the policymakers who have put in place the market opening reforms. 